\title{
Soil Respiration and Photosynthesis of Leaves in Greenhouse Cultivation Cherry Tomato
}

\author{
Yinli LIANG \\ Institute of Soil and Water Conservation \\ Northwest A\&F University \\ Yangling, Shaanxi, 712100, China \\ e-mail: liangyl@ms.iswc.ac.cn
}

\author{
Tianli BAO \\ Institute of Soil and Water Conservation \\ Northwest A\&F University \\ Yangling, Shaanxi, 712100, China \\ e-mail: b973583030@163.com
}

\author{
Lan MU \\ Northwest Historical Environment and Economic and Social Development Research Institute \\ Shaanxi Normal University \\ Xi'an, Shaanxi, 710062, China \\ e-mail: mulan820706@163.com
}

\begin{abstract}
To explore the optimum growth condition of cherry tomato (Lycopersiconesculentum), the cherry tomato was used to study the soil respiration and photosynthesis of leaves under greenhouse and outdoor condition with Lou soil and loessial soil during fruiting period in the year 2013 and 2014.The results showed that from early fruiting stage to later fruiting stage, net photosynthetic rate decreased firstly then increased, soil respiration decreased, the yields of cherry tomato increased firstly then decreased to a lower value at later fruiting stage. In addition, net photosynthetic rate was the highest in Lou soil in outdoor and lowest in loessial soil in greenhouse, Fruit yields were the highest in Lou soil in greenhouse. Therefore, tomato in Lou soil in outdoor is optimum treatment for preserving high net photosynthetic rate and low soil respiration.
\end{abstract}

Keywords-soil respiration; net photosynthetic rate; cherry tomato; greenhouse

\section{INTRODUCTION}

Tomatoes have an important position in the development of global economy and food supply; it's also one of the most important vegetable in China (Qi et al., 2006).Photosynthesis of leaf is the basic unit of matter accumulation of plant during the productive process; it's also an important part of analyzing the impact of environment on growth and metabolism of plant (Reddy et al., 2004). What's more, it's the basis of crop growth and critical factor of productivity (Zhu et al., 2007).Meanwhile, soil respiration is the main process about the releasing $\mathrm{CO}_{2}$ of land ecosystem into atmosphere, and it's one of the largest flux of the global carbon cycle. To clear soil $\mathrm{CO}_{2}$ emission in different ecological system has very important significance for understanding of terrestrial ecosystem carbon cycle and carbon balance(Yan et al., 2009). Accordingly, the objectives of the current research are: (1) to investigate the soil respiration, photosynthesis, in different cultivation conditions and soil types in cherry tomato during the growing season (2) to analyze the effects of the environmental factors on tomato growth under greenhouse conditions. (3) to estimate the appropriate soil and suitable cultivation condition for tomato production.

\section{MATERIAL AND METHODS}

The experiments were carried out in the experimental sites in greenhouse and outdoor at Institute of the Soil and Water Conservation, Northwest A\&F University, Yangling (34'12"-34'20'"N; 108'-108'7E, elevation 560m), Shaanxi, China, from May to September in 2013 and 2014, respectively. Soil waterholding capacity was $220 \mathrm{~g} \mathrm{~kg}^{-1}$ and the soilbulk density of loessial soil was $1.09 \mathrm{~g} \mathrm{~cm}^{-3}$, and Soil waterholding capacity was $240 \mathrm{~g} \mathrm{~kg}^{-1}$ and the soilbulk density of Lou soil was $1.2 \mathrm{~g} \mathrm{~cm}^{-3}$ (table I).

TABLE I. PHysic-CHEMICAL PROPERTIEs OF TESTED SOIL

\begin{tabular}{lll}
\hline Soil & Loessialsoil & Lousoil \\
\hline Organic matterg. $\mathrm{kg}^{1}$ & 8.73 & 9.60 \\
Total $\mathrm{Ng} \cdot \mathrm{kg}^{-1}$ & 0.42 & 0.52 \\
Avai.Nmg $\mathrm{kg}^{-1}$ & 9.78 & 9.57 \\
Total P g. $\mathrm{kg}^{-1}$ & 0.56 & 0.64 \\
Avai.Pmg $\cdot \mathrm{kg}^{-1}$ & 24.75 & 26.93 \\
Avai. $\mathrm{Kmg} \cdot \mathrm{kg}^{-1}$ & 91.92 & 102.37 \\
PH & 7.2 & 7.9
\end{tabular}

There were four treatments including GH (loessial soil in greenhouse), GL (Lou soil in greenhouse), $\mathrm{OH}$ (loessial soil in outdoor) and OL (Lou soil in outdoor). Tomato plants (Golden radio cherry tomato, a common variety) were transplanted at pillar that the depth was $1 \mathrm{~m}$ and the diameter was $31.5 \mathrm{~cm}$, using a randomized block design with 10 replications, and two rows of tomato plants with interrow spacing of $60 \mathrm{~cm}$ and interplant spacing of $50 \mathrm{~cm}$ were transplanted in each pillar. Treatments were established on 15 May 2013 and 5 May 2014,end the experiment on 15 September 2013 and 19 September 2014. After treatments were established fertilizers were applied with $2 \mathrm{~g} \mathrm{~N}$ (urea) and $2 \mathrm{~g} \mathrm{P}_{2} \mathrm{O}_{5}$ (diammonium phosphate) and $2 \mathrm{~g} \mathrm{~K}_{2} \mathrm{O}$ for each pillar. Applied fertilizer 1 timesper month in the fruiting stage in order to satisfy the demands of the growth of plants. 
Measuring items and methods: Fruits of cherry tomato was harvested every seven days and counted on the yield. Fruit stage was divided into the early fruiting stage( middle of May to the middle of June), fruit flourish stage(middle of June to middle of July) and later fruiting stage (middle of July to middle of August). Net photosynthetic rate was measured during the growing season (July-September) in 2013 and 2014 using a LICOR-6400 portable photosynthesis system, three leaves were measured with phototropism consistent. Soil respiration was measured during the growing season (July-September) in 2013 and 2014 using a LICOR6400 portable photosynthesis system equipped with a LICOR 6400-9 soil respiration chamber. Polyvinyl chloride soil collars $10.4 \mathrm{~cm}$ in diameter and $5 \mathrm{~cm}$ in height were used for the measurements. To minimize the soil surface disturbance-induced $\mathrm{CO}_{2}$ efflux, the collars were installed to a depth of $6 \mathrm{~cm}$ at least $24 \mathrm{~h}$ prior to each measurement. Three replicate measurements were made on each collar on the observation days. The collar was placed near the plants (5 $\mathrm{cm}$ from the plant), interplants $(25 \mathrm{~cm}$ from the plants) and intersrows (in the middle of four plants, approximately 35 $\mathrm{cm}$ from the plants) on each experimental plot. All the measurements were performed between 9:00 and 11:00 h. At the same time, soil temperature was measured through thermal detector attach with the LICOR-6400.

Statistical analysis: the figure was made using the Origin 8.5 software. The relationship of soil respiration and soil temperature was analyzed with Sigma plot.

\section{RESULTS}

\section{A. Effect of Environmental Factors and Soil Types on Soil Respiration and Photosynthesis of Leaves of Cherry Tomato}

The net photosynthetic rate was the highest in the early fruiting stage, it decreased then increased along with the growing period.Soil respiration decreased along with the growing period, while it decreased then increased in loessial soil in outdoor and in Lou soil in outdoor in 2014 (Table2).The net photosynthetic rate was higher in Lou soil than in loessial soil and soil respiration was higher in loessial soil than in Lou soil under the same cultivation condition. Net photosynthetic rate was better in outdoor than in greenhouse and soil respiration was with the opposite while under the same of the soil types.

The results showed the yield was higher in Lou soil than in loessial soil under the same cultivation condition (Table II). What's more, it was better in greenhouse than in outdoor under the same of the soil types.In the whole, yield was higher in Lou soil in greenhouse than in others treatments. The varieties of cherry tomato were different in two years, but the effect of treatments on yield was consistent.
TABLE II. ENVIRONMENT AL FACTORS AND SOIL TYPES ON SOIL RESPIRATION AND PHOTOSYNTHESIS

\begin{tabular}{lcccccc}
\hline & & & $\mathrm{GH}$ & $\mathrm{GL}$ & $\mathrm{OH}$ & $\mathrm{OL}$ \\
\hline Early fruiting & $\mathrm{Pn}$ & 2013 & $8.5 \mathrm{~d}$ & $12.4 \mathrm{c}$ & $14.6 \mathrm{~b}$ & $16.7 \mathrm{a}$ \\
stage & & 2014 & $4.6 \mathrm{c}$ & $12.4 \mathrm{~b}$ & $14.7 \mathrm{ab}$ & $18.5 \mathrm{a}$ \\
& $\mathrm{Sr}$ & 2013 & $5.4 \mathrm{a}$ & $4.4 \mathrm{~b}$ & $3.7 \mathrm{c}$ & $2.5 \mathrm{~d}$ \\
& & 2014 & $7.2 \mathrm{a}$ & $6.3 \mathrm{~b}$ & $5.0 \mathrm{c}$ & $3.1 \mathrm{~d}$ \\
& $\mathrm{Pn}$ & 2013 & $1.4 \mathrm{~d}$ & $4.6 \mathrm{c}$ & $8.4 \mathrm{~b}$ & $10.1 \mathrm{a}$ \\
Fruit flourish stage & $\mathrm{Pn}$ & & & \\
& & 2014 & $1.8 \mathrm{~cd}$ & $3.0 \mathrm{c}$ & $6.2 \mathrm{~b}$ & $15.7 \mathrm{a}$ \\
& $\mathrm{Sr}$ & 2013 & $3.23 \mathrm{a}$ & $2.9 \mathrm{~b}$ & $2.7 \mathrm{bc}$ & $2.2 \mathrm{c}$ \\
& & 2014 & $3.4 \mathrm{a}$ & $3.3 \mathrm{a}$ & $1.9 \mathrm{~b}$ & $1.2 \mathrm{c}$ \\
Later fruiting stage & $\mathrm{Pn}$ & 2013 & $2.9 \mathrm{~cd}$ & $4.6 \mathrm{c}$ & $10.7 \mathrm{~b}$ & $13.2 \mathrm{a}$ \\
& & 2014 & $3.2 \mathrm{c}$ & $3.4 \mathrm{c}$ & $7.2 \mathrm{~b}$ & $9.8 \mathrm{a}$ \\
& $\mathrm{Sr}$ & 2013 & $1.6 \mathrm{~b}$ & $2.1 \mathrm{a}$ & $2.1 \mathrm{a}$ & $1.6 \mathrm{~b}$ \\
Fruit yield $(\mathrm{kg})$ & & 2014 & $2.7 \mathrm{~b}$ & $2.8 \mathrm{~b}$ & $3.2 \mathrm{a}$ & $3.0 \mathrm{ab}$ \\
& & 2013 & $1.1 \mathrm{~b}$ & $1.2 \mathrm{a}$ & $0.9 \mathrm{~d}$ & $1.0 \mathrm{c}$ \\
& & 2014 & $1.0 \mathrm{~b}$ & $1.1 \mathrm{a}$ & $0.8 \mathrm{~d}$ & $0.9 \mathrm{c}$ \\
\hline
\end{tabular}

* Pn: Net photosynthetic rate (umol. $\left.\mathrm{m}^{-2} \cdot \mathrm{s}^{-1}\right)$, Sr: Soil respiration (umol. $\mathrm{m}^{-2} . \mathrm{s}^{\mathrm{s}}$ ) **GH: (loessial soil in greenhouse, GL: Lou soil in greenhouse, $\mathrm{OH}$ : loessial soil in outdoor,

OL: Lou soil in outdoor.

\section{B. Relationship of Soil Respiration and Soil Temperature}

The effect of soil temperature on soil respiration were significant at $\mathrm{p}<0.05$ (Fig.1). Correlation analysis indicated that soil respiration was significantly correlated with temperature of loessial soil $\left(\mathrm{R}^{2}=0.9038\right.$ greenhouse; $\mathrm{R}^{2}=0.6552$ outdoor). Soil respiration was significantly correlated with temperature of Lou soil $\left(\mathrm{R}^{2}=0.4545\right.$ greenhouse; $\mathrm{R}^{2}=0.3388$ outdoor). At the same time, soil temperature could significantly affected soil respiration. Soil respiration increased with the increasing of soil temperature. There are significantly correlations between soil respiration and soil temperature in different cultivation conditions and soil types.

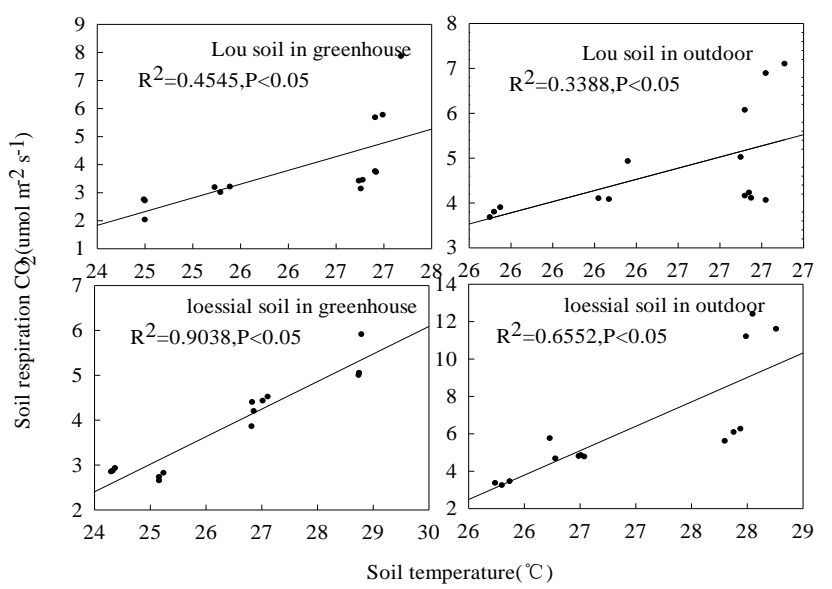

Figure 1. Relationship of soil respiration and soil temperature

\section{DisCUSSION AND CONCLUSIONS}

The effect of cultivation conditions and soil types on net photosynthetic rate and soil respiration were significant at $\mathrm{p}<0.05$. As a whole, net photosynthetic rate was highest in 
Lou soil in outdoor and lowest in loessial soil in greenhouse. Soil respiration was in contrast with net photosynthetic rate. Net photosynthetic rate decreased with the consumption of $\mathrm{CO}_{2}$ from greenhouse crops because the greenhouse can't conduct timely gas exchange and ventilation (Bian et al., 2012). Microorganisms need consume more energy and produce more $\mathrm{CO}_{2}$ for resisting poor environment (Zeng et al., 2009). Net photosynthetic rate was higher in Lou soil than in loessial soil under the same cultivation condition, soil respiration was opposite with it. The texture of Lou soil is sticky and the storage of water and nutrients is better so that it's advantageous to the transportation of photosynthate for providing enough nutrients for plant growth, so net photosynthetic rate is higher than loessial soil. Soil respiration was higher in loessial soil because the texture of loessial soil is loose and soft with high decomposition rate of soil organic matter (Wang et al., 2012).

The effect of cultivation conditions and soil types on yield were significant at $\mathrm{p}<0.05$. Overall, the yield was higher in Lou soil in greenhouse. Growth and biomass of allocation of plant in each living conditions were correlated with environmental factors (Wang et al., 2008; Geng et al., 2008). The research showed that the root is larger and the yield is higher in the greenhouse because larger root is beneficial to absorb water and nutrients from the soil (Wang et al., 2013). The yield is better in Lou soil because the texture of Lou soil is sticky and the storage of water and nutrients is better so that it can ensure the nutrient uptake from root.The effect of soil temperature on soil respiration were significant at $p<0.05$. Correlation analysis indicated that soil respiration was correlated with temperature of Lou soil and loessial soil. At the same time, soil temperature could be significantly affected with soil respiration. What's more, soil respiration increased with the increase of soil temperature. The seasonal variation of soil respiration was mainly affected by the change of soil temperature (Yan et al., 2009).

Conclusions: net photosynthetic rate of tomato was highest in Lou soil in outdoor and lowest in loessial soil in greenhouse. Soil respiration was in contrast with net photosynthetic rate.So soil respiration was higher in greenhouse.Fruit yields were the highest in Lou soil in greenhouse. Therefore, tomato in Lou soil in outdoor is optimum treatment for preserving high net photosynthetic rate and low soil respiration.

\section{ACKNOWLEDGEMENTS}

This work was financially supported by the National Science and Technology Support Program, No.2014B AD14B006.

\section{REFERENCES}

[1] Qi NM, Yang SJ, Zhu LY, Xing Q, et al. 2006. ActaAgriculturae Shanghai. 22: 140

[2] Ramachandra Reddy A, Chaitanya KV, Vivekanandan M. 2004. Journal of Plant Physiology.161: 1189.

[3] Zhu YY, He KN, Tang DF, et al.2008.Research of Soil and Water Conservation. 14: 92.

[4] Yan JX, Qin ZD, Zhang YH, Li HJ. 2009.ActaEcologicaSinica. 29: 6366-6376.

[5] Bian ZH, Wang Y, Hu XH, Zou ZR, Zhang J.2012. Journal of Northwest A\&F University(Nat. Sci. Ed.) .40: 136.

[6] Zeng LS, Cui DJ, Li JL, Jin SA, Zhao XF. 2009.Plant Nutrition and Fertilizer Science. 15: 865.

[7] Wang XY, LI YL, Zhao XY, Mao W, et al. 2012. ActaEcologicaSinica. 32: 4890.

[8] Wang W, Peng SS, Fang JY. 2008. Arid Zone Research. 25: 90-97.

[9] Geng HL, Wang YH, Wang FY, Jia BR. 2008. ActaEcologicaSinica. $28: 4629$

[10] Wang YZ, Liu XW, Sun HY, Zhang XY, Zhang LR.2013. Chinese Journal of Eco-Agriculture. 21: 282. 